\title{
Data Envelopment Analysis and Analytics Software for Optimizing Building Energy Efficiency
}

\author{
Zinovy Radovilsky, California State University, East Bay, USA \\ Pallavi Taneja, Media.Monks, USA \\ Payal Sahay, Buzzer Sports, USA
}

\begin{abstract}
This research was motivated by the need to identify the most effective data envelopment analysis (DEA) model and associated data analytics software for measuring, comparing, and optimizing building energy efficiency. By analyzing literature sources, the authors identified several gaps in the existing DEA approaches that were resolved in this research. In particular, the authors introduced energy efficiency indices like energy consumption per square foot and per occupant as a part of DEA models' outputs. They also utilized inverse and min-max normalized output variables to resolve the issue of undesirable outputs in the DEA models. The evaluation of these models was done by utilizing various data analytics software including Python, R, Matlab, and Excel. The authors identified that the CCR DEA model with inverse output variables provided the most reliable energy efficiency scores, and the Python's PyDEA package produces the most consistent efficiency scores while running the CCR model.
\end{abstract}

\section{KEYWORDS}

Business Data Analytics, CCR and BCC Models, DEA, Optimization, Undesirable Variables in DEA

\section{INTRODUCTION}

The consumption of energy in the building sector has been an important part of the overall energy usage in the United States and on the global scale. According to the U.S. Energy Information Administration, residential and commercial buildings account for about $40 \%$ of the total U.S. energy consumption (EIA, 2020).

Identification and comparison of energy efficiency in buildings is based on utilizing a variety of metrics. For example, a very commonly used metric in the U.S. and globally for building energy performance is the energy use intensity (EUI), which is also applied for Energy Star Certification (Energy Star, 2018). This certification shows that comparing the energy use of buildings with others nationwide helps to effectively identify the opportunities for potential savings and best practices that can be replicated (Energy Star, 2018). Another common index for measuring energy efficiency is the energy efficiency index (EEI), also known as the building energy index. It is defined as the ratio of energy input $(\mathrm{kWh})$ to a factor related to energy used, typically, building floor space (Kavousian et 
al., 2015). A variety of alternative indices for building energy performance has been also discussed in a paper by Goldstein and Eley (2014).

Measuring building energy performance usually takes into consideration a wide range of different factors, including energy usage, floor space, number of occupants, climate condition, energy efficiency of the equipment used, outdoor temperatures and others (Lee \& Lee, 2009). There is also a number of methods applied to identify and compare energy efficiency in buildings. These methods can be summarized into four groups: simulation, regression analysis, neural networks, and data envelopment analysis (Ashuri et al., 2019; Wang et al., 2015; Lee \& Lee, 2009; Lee, 2008). Each of these methods contains some benefits over other methods and, at the same time, limitations and drawbacks, a detailed description of which have been discussed in literature sources, e.g., Ashuri et al. (2019).

In this paper, the focus is on applying Data Envelopment Analysis (DEA) for measuring and comparing building energy efficiency. While the other three methods (simulation, regression, and neural networks) are being extensively used for data prediction and data analytics, the DEA method is the only one that is directly applied, and very successfully, to identify, compare, and optimize efficiency of similar units for an organization or between organizations. DEA allows to establish optimal efficiency targets and it does not rely on assumptions of relationships between input resources and output results. DEA is also a highly popular method for comparing and optimizing efficiency of similar units in various industries, for example, health care, hotels, and production units (Zakowska \& Maciek, 2020; Nguyen \& Nguyen, 2019; Liu and Zhang, 2017).

The DEA application in measuring and comparing building energy efficiency is still a developing area in business data analytics, and, therefore, is a subject of an ongoing discussion in academic literature. Molinos-Senante et al. (2016) consider several issues for DEA approaches. One of these issues focuses on architectural factors (compactness, building shape, etc.), and another - on energy management issues such as equipment efficiency and operations strategy. Some researchers recognize one more important DEA issue of applying a variety of DEA models and software in performing energy efficiency comparison for buildings (Iliyasu et al., 2015; Wang, 2017; Yoon \& Park, 2017, $\mathrm{Xu}$ et al., 2020).

This research is motivated by the need to identify the most effective DEA model and associated data analytics software for measuring and comparing buildings' energy efficiency. For that, the authors conduct the academic literature review to understand existing DEA methodologies for measuring and comparing energy efficiency in buildings. In addition, the appropriate DEA models, input and output variables, and data analytics software have been identified for comparing and optimizing buildings' energy efficiency. Finally, the authors compare internal consistency of various DEA models and DEA-related software packages to identify the most reliable and effective DEA model for energy efficiency optimization in buildings. This paper is referring, in general, to data analytics professionals that have necessary skills to apply the DEA methods and software presented in the paper. Based on utilizing these methods and software packages, the data analytics professionals can develop decision support systems (DSS) that will extend the usage of DEA models to end-users, e.g., building energy managers, engineers, and specialists.

This paper's structure includes five main sections. After the Introduction, the Literature Review section presents the existing DEA research on measuring and comparing building energy efficiency. The next section on Methodology provides detailed steps of the research methodology including input and output variables, DEA models, and DEA-related analytics software. The following section presents a comprehensive analysis, comparison of results, and discussion of energy efficiency optimization in buildings using the DEA models and analytics software packages. The Conclusion section provides a summary of the research and its results described in this paper. 


\section{LITERATURE REVIEW}

\section{Data Envelopment Analysis}

Data Envelopment Analysis (DEA) is an efficiency evaluation approach, which is used for comparing the performance of similar units and identifying optimal in efficiency unit(s) in an organization or between organizations. The similar units in DEA are referred to as Decision Making Units (DMUs). The efficiency of a DMU is measured relative to all other DMUs. Comparison of peer groups enables the stakeholders (building owners, building managers, investors, etc.) to derive actionable information from the building energy data that help enhance energy efficiency of buildings (Mathew et al., 2015).

One of the most common DEA models, which is frequently discussed in the literature and widely used in practice, is the Charnes-Cooper-Rhodes (CCR) model (Charnes et al., 1978). It can be presented as a linear programming (LP) optimization model in the following way (Cooper et al., 2011):

$\max z=\sum_{r=1}^{s} u_{r} y_{r o}$

subject to

$\sum_{r=1}^{\mathrm{s}} \mathrm{u}_{\mathrm{r}} \mathrm{y}_{\mathrm{rj}}-\sum_{\mathrm{i}=1}^{\mathrm{m}} \mathrm{v}_{\mathrm{i}} \mathrm{x}_{\mathrm{ij}} \leq 0 \mathrm{j}=1,2, \ldots, \mathrm{n}$,

$\sum_{\mathrm{i}=1}^{\mathrm{m}} \mathrm{v}_{\mathrm{i}} \mathrm{x}_{\mathrm{io}}=1$

$u_{r}, v_{i} \geq 0 ; r=1,2, \ldots, s, i=1,2, \ldots, m$.

In the CCR model's formulation (1), the assumption is that there are $n$ DMUs ( $n$ buildings in case of this research) to be evaluated. Each DMU employs $m$ different inputs to produce $s$ different outputs. Specifically, $D M U_{j}$ consumes amount $x_{i j}$ of input $i$ and produces amount $y_{r j}$ of output $r$. Parameters $u_{r}$ and $v_{i}$ are the variable weights to be determined by solving the CCR model in formulation (1). The CCR model is built on the notion of efficiency as a ratio of outputs to the relative inputs. A DMU's efficiency obtained in the model is never absolute as it is always measured relative to other DMUs (Cooper et al., 2011). If the solution for DMU $O$ in formulation (1) is equal to 1 , then this building is considered $100 \%$ efficient relative to other buildings in the CCR model.

The CCR model also assumes constant returns to scale (CRS) between inputs and outputs (Banker et al., 2004). This implies that an increase in a DMU's inputs leads to a proportionate increase (or decrease) in its outputs, i.e., there is a one-to-one linear relationship between inputs and outputs. For example, if a $10 \%$ increase in inputs yields a $10 \%$ increase in outputs, the DMU is operating at constant returns to scale. This means that no matter what scale the DMU operates at, its efficiency will remain unchanged.

Another popular DEA model that is frequently discussed in the literature sources is the Banker, Charnes and Cooper (BCC) model (Banker et al., 1984). It can also be presented as an LP optimization model (Banker et al., 2004) in the following way:

$\max z=\sum_{r=1}^{\mathrm{s}} \mathrm{u}_{\mathrm{r}} \mathrm{y}_{\mathrm{ro}}-\mathrm{u}_{\mathrm{o}}$

subject to 
$\sum_{r=1}^{\mathrm{s}} \mathrm{u}_{\mathrm{r}} \mathrm{y}_{\mathrm{rj}}-\sum_{\mathrm{i}=1}^{\mathrm{m}} \mathrm{v}_{\mathrm{i}} \mathrm{x}_{\mathrm{ij}}-\mathrm{u}_{\mathrm{o}} \leq 0 \mathrm{j}=1,2, \ldots, \mathrm{n}$,

$\sum_{\mathrm{i}=1}^{\mathrm{m}} \mathrm{v}_{\mathrm{i}} \mathrm{x}_{\mathrm{io}}=1$

$\mathrm{u}_{\mathrm{r}}, \mathrm{v}_{\mathrm{i}} \geq 0 ; \mathrm{u}_{\mathrm{o}}$ is free of sign; $\mathrm{r}=1,2, \ldots, \mathrm{s}, \mathrm{i}=1,2, \ldots, \mathrm{m}$.

Being similar to the CCR model, the BCC model's formulation (2) contains one extra weight variable, $u_{o}$, which makes it possible to alternate returns-to-scale evaluations. This means that a DMU's input increase or decrease does not necessarily produce a proportional (constant) change in its outputs, and, thus, the BCC model is considered a model with variable returns to scale (VRS). VRS implies that as a DMU changes its scale of operations, its efficiency will either increase, decrease, or remain the same.

Analysis of research literature on utilizing DEA in measuring and optimizing building energy efficiency shows that authors utilize both CCR/CRS and BCC/VRS models with various options and extensions in developing and comparing energy efficiency in buildings. Grösche (2009), MolinosSenante et al. (2016), and Wang et al. (2015) apply the CCR model to identify and compare energy efficiency performance in office and residential buildings. Ashuri et al. (2019) employ a combination of CCR and BCC models to compare and optimize energy efficiency of multi-family properties in various U.S. states. Lee and Lee (2009) utilize, the BCC model to identify and optimize efficiency of building energy management in government buildings. Even though some of these research papers describe the usage of both CCR and BCC models, there is no discussion or comparison of the merits associated with each type of these DEA models in measuring buildings' energy efficiency (Ashuri et al., 2019; Xu et al., 2020). Therefore, in this research it is considered as a gap in the existing DEA research on comparing and optimizing energy efficiency in buildings.

\section{Input and Output Variables for DEA Models}

The reviewed literature sources describe a variety of input and output variables used in DEA models for building energy measurement and comparison. Among input variables $x_{i j}$ in formulations (1) and (2), energy consumption (in $\mathrm{kWh}$ ) and energy cost (in \$) are the most common (Ashuri et al., 2019; Grösche, 2009; Lee \& Lee, 2009; Xu et al., 2020). Other input variables applied in the DEA models may include EUI (Lee, 2008; Wang et al., 2015) and outdoor temperature (Ashuri et al., 2019). The inclusion of EUI as an input variable in the DEA model is arguable as it measures energy consumption per square foot of building space per year, and thus, represents a result (output) of building energy usage. Therefore, EUI or similar energy efficiency indices should be considered as output variables in the DEA model. In addition, the outdoor temperature may not be relevant as an input variable if all campus buildings are in the same climate area.

According to the literature review, the output variables $y_{r j}$ in formulations (1) and (2) may consist of: building's floor space and number of occupants, energy consumption per occupant and per square foot, and average outdoor temperature (Ashuri, et al., 2019; Grösche, 2009; Lee, 2008; Lee \& Lee, 2009; Molinos-Senante et al., 2016). The authors of this paper would like to argue that some of these measures, i.e., floor space and number of occupants, are not output results of energy consumption. They merely represent the inputs to the energy efficiency measurements. Moreover, the actual utilization in practice of energy efficiency indices like EUI and energy consumption per number of occupants (Fairey \& Goldstein, 2016; Goldstein \& Eley, 2014; Orvis et al., 2016, Xu et al., 2020) show that floor space and number of occupants in a building are, in fact, applied as inputs to energy efficiency indices. Therefore, a building's space area and number of occupants must be considered 
as input variables in DEA. Conversely, energy efficiency indices like energy consumption per square foot of space area and per occupant should be applied as output variables for the DEA models.

\section{DEA Software Packages}

In reviewing the literature sources, it was identified that only a handful number of papers discuss the usage of DEA-related analytics software applied for building energy efficiency. Yoon and Park (2017) describe using Matlab software in comparing building energy performance. Wang (2017) applies Excel Solver to run a DEA model for measuring and comparing building energy efficiency. Iliyasu et al. (2015) discuss different DEA packages including, for example, Excel-based DEA Solver and R-based rDEA software. While discussing these packages, they do not provide any comparison between these packages and do not identify which packages are commonly used in various industries. Daraio et al. (2019) review DEA tools for productivity and efficiency analysis based on the following software options: AMPL, GAMS, Mathematica, Matlab, R, SAS, and STATA. They also do not provide any comparison of these DEA tools or identify the most popular of them, but point out that a systematic comparison and assessment of the reviewed software could be an "interesting avenue for further research."

Even with a rigorous literature search, the authors of this paper could not identify any literature source that would discuss applicability and efficiency of data analytics software and their DEArelated packages in measuring and comparing energy efficiency in buildings. It was not possible to identify which DEA-related package(s) is(are) recognized as most popular in building energy efficiency analysis. All this is also considered as one more gap in the existing DEA research on building energy efficiency.

\section{METHODOLOGY}

Based on the literature review and revealed gaps in DEA literature sources, the primary objective of this research is to identify the most effective DEA model(s) and associated data analytics software for measuring, comparing, and optimizing energy efficiency in buildings. This will require to analyze and compare energy efficiency in buildings by applying different DEA models, CCR and BCC, and various data analytics software.

The research methodology in this study includes the following steps:

1. Select a data set containing buildings' energy efficiency parameters.

2. Recognize DEA input/output variables.

3. Identify DEA models to be used for measuring, comparing, and optimizing building energy efficiency.

4. Choose data analytics software packages to apply the selected DEA models.

5. Identify and compare energy efficiency of buildings in the employed data set using the selected DEA models and analytics software packages.

6. Interpret the energy efficiency results and identify the most effective DEA model and analytics software package for energy efficiency optimization in buildings.

Step 1. In this research, the authors employ a data set that contains energy-related parameters of 17 buildings on a campus of a U.S. organization's headquarters in the San Francisco Bay Area. For each building on this campus, the data set contains monthly building parameters like energy consumption, number of occupants, space area per building, and monthly energy cost. In addition, the data set incorporates some energy-related ratios including energy effective rate, consumption per occupant and per space. The summary statistics of the data set parameters are presented in Table 1. 
Table 1. Summary statistics of input and output variables for energy efficiency DEA

\begin{tabular}{|l|l|l|l|l|l|l|l|}
\hline \multirow{2}{*}{$\begin{array}{l}\text { Buildings, } \\
\text { Summary } \\
\text { Statistics }\end{array}$} & \begin{tabular}{l} 
Input Variables \\
\cline { 2 - 7 } \\
CWhsumption,
\end{tabular} & $\begin{array}{l}\text { Number of } \\
\text { Occupants }\end{array}$ & $\begin{array}{l}\text { Space } \\
\text { Area, } \\
\text { Sq. Ft. }\end{array}$ & $\begin{array}{l}\text { Energy } \\
\text { Cost, \$ }\end{array}$ & $\begin{array}{l}\text { Effective } \\
\text { Rate, \$/ } \\
\text { kWh }\end{array}$ & $\begin{array}{l}\text { Consumption } \\
\text { per Occupant, } \\
\text { kWh/Occupant }\end{array}$ & $\begin{array}{l}\text { Consumption } \\
\text { per Space, } \\
\text { kWh/Sq. Ft. }\end{array}$ \\
\hline Mean & 92217.4 & 332.8 & 81530.5 & 11949.4 & 0.1331 & 327.7951 & 1.2301 \\
\hline Median & 84148.6 & 339.0 & 85913.0 & 10598.0 & 0.1270 & 255.8206 & 1.0420 \\
\hline Minimum & 23993.7 & 76.0 & 14415.0 & 3929.4 & 0.1132 & 79.9789 & 0.6254 \\
\hline Maximum & 265360.5 & 531.0 & 194100.0 & 33690.1 & 0.1638 & 817.2755 & 2.9482 \\
\hline $\begin{array}{l}\text { Standard } \\
\text { Deviation }\end{array}$ & 52509.1 & 125.5 & 37326.4 & 6445.1 & 0.0153 & 217.9440 & 0.5869 \\
\hline $\begin{array}{l}\text { Coefficient } \\
\text { of Variation }\end{array}$ & $56.9 \%$ & $37.7 \%$ & $45.8 \%$ & $53.9 \%$ & $11.5 \%$ & $66.5 \%$ & $47.7 \%$ \\
\hline
\end{tabular}

Each building on the described campus has various square footage, number of occupants and energy usage, which leads to a significant variability of input and output energy measurements between the buildings. For example, the coefficient of variation (a ratio of standard deviation and mean) for consumption is $56.9 \%$, for number of occupants $-37.7 \%$, and for space area $-45.8 \%$. A similar high variability exists between the buildings' output variables (with exception of effective rate). All this is indicative of a variety of buildings and their energy parameters that are considered in this research. Therefore, the produced analytical results of measuring and comparing energy efficiency may be generalized for any campus with office buildings of various sizes, population, and energy parameters.

Step 2. Based on the previously made comments in the Literature Review about the input/output variables for DEA models, the following four input variables are selected for each building (Table 1):

- Energy consumption per month, kWh

- Number of occupants, units

- $\quad$ Space (floor) area, sq. ft.

- $\quad$ Energy cost per month, \$.

Also, for each building, the following three output variables are identified (Table 1):

- Effective rate of energy consumption, $\$ / \mathrm{kWh}$

- Energy consumption per occupant, $\mathrm{kWh} /$ population

- Energy consumption per square foot of space, $\mathrm{kWh} / \mathrm{sq}$. ft.

The introduced set of output variables truly reflect the nature of building energy efficiency outputs expressed by energy indices (ratios), whereas the set of inputs variables characterize the important building parameters that energy efficiency depends on.

Some DEA authors raise a concern that the usage of ratio variables, e.g., effective rate or consumption per occupant, may violate one of the main assumptions of an efficiency measure in DEA - the convexity axiom (Ashuri et al., 2019; Emrouznejad \& Amin, 2009; Wang, 2017). However, this issue can be resolved by developing a modified CCR or BCC model that can incorporate ratio output or input variables (Sopko \& Kocisova, 2018; Olesen et al., 2015; Olesen et al., 2017). Moreover, modern data analytics software packages for DEA can incorporate ratio variables in energy efficiency analysis without losing integrity of DEA results.

In a traditional DEA model, the goal is to maximize outputs relevant to their inputs. Contrary to that, the DEA output variables, e.g., effective rate $(\$ / \mathrm{kWh})$ or consumption per occupant $(\mathrm{kWh} /$ Occupant), are those that actually need to be lower for achieving higher energy efficient buildings. 
Therefore, these variables represent "undesirable outputs" in terms of the DEA model. Literature sources provide a number of approaches on how to deal with undesirable outputs that can be summarized into several major groups of methods: (a) ignoring undesirable outputs (Halkos \& Polemis, 2018; Yang \& Pollitt, 2009); (b) treating undesirable outputs as inputs ((Jahanshahloo et al., 2005; Seiford \& Zhu, 2002); and (c) transforming undesirable outputs into a desirable form (Fare \& Grosskopf, 2004; Homayounfar et al., 2014; Scheel, 2001). In this research, the authors utilize two relatively simple ways of undesirable variable's transformation: inverse transformation and min-max normalization.

The inverse transformation converts an undesirable output $y_{r j}$ in formulations (1) or (2) into a desirable form by using the following formula:

$Y_{r j}=1 / y_{r j}$

Applying these transformed variables in a DEA model, will maximize outputs $\left(Y_{r j}\right)$, and, simultaneously, minimize the real output variables $\left(y_{r j}\right)$, which would be required for efficient energy performance.

The min-max normalization allows to normalize output variables on a uniform scale using the minimum and maximum values of each output variable, $\min \left(y_{r j}\right)$ and $\max \left(y_{r j}\right)$ :

$Y_{r j}=\left[y_{r j}-\max \left(y_{r j}\right)\right] /\left[\min \left(y_{r j}\right)-\max \left(y_{r j}\right)\right]$

Based on formula (4), the values of outputs are normalized between 0 and $1(0 \%$ and $100 \%)$, The smaller the value of $y_{r j}$, the higher the value of $Y_{r j}$. Thus, these normalized variables in a CCR or BCC model can be applied to identify proper efficiency measures for each DMU.

Step 3. The next step in this research is selection of the appropriate DEA model(s). The authors apply the CCR model with CRS in formulation (1) and the BCC model with VRS in formulation (2). The transformation of undesirable variables using the inverse transformation (3) and min-max utilization (4) are also utilized for both models.

Step 4. In this research, four analytics software options are being employed: Microsoft Excel, R, Python, and Matlab. All of them are popular software in modern business data analytics. They also contain specific packages or add-ins (in case of Excel) to run DEA-based models. In Excel, the authors utilize the Excel Solver add-in, which is applied for solving linear and non-linear optimization models. The R's rDEA package is employed for both CCR and BCC models. The authors also apply the Python's PyDEA package to run the discussed DEA models. In Matlab, the built-in package Data Envelopment Analysis Toolbox (DEA Toolbox) - is utilized to perform the energy efficiency analysis with the same models and output variables.

The final Steps 5 and $\mathbf{6}$ of this methodology on identifying and comparing buildings' energy efficiency and interpreting results of this comparison are presented in the next section of this paper.

\section{ENERGY EFFICIENCY ANALYSIS AND INTERPRETATION OF RESULTS}

Based on formulations (1) and (2), the CCR and BCC models are run separately for all 17 DMUs using the respective inverse and min-max normalized output variables with different analytics software packages in Excel, R, Python, and Matlab (see Table 2).

As can be seen from Table 2, for each DMU, we apply four DEA software packages and four types of output variables, two variables for the CCR and two - for the BCC models. These lead to 
the development of a set with $16(4 \mathrm{x} 4)$ efficiency scores for each of the 17 DMUs. The efficiency score of 1.0 represents a building's optimal energy efficiency of $100 \%$, and the score of less than 1.0 implies that the energy efficiency in a building is not optimal.

Table 2. Analytics software applications and DEA methods

\begin{tabular}{|c|c|c|c|c|c|}
\hline \multirow[b]{2}{*}{ Analytics Software } & \multirow[b]{2}{*}{$\begin{array}{l}\text { Software Package } \\
\text { (Add-in) }\end{array}$} & \multicolumn{2}{|c|}{ CCR Model } & \multicolumn{2}{|c|}{ BCC Model } \\
\hline & & $\begin{array}{l}\text { Inverse } \\
\text { Output } \\
\text { Variables }\end{array}$ & $\begin{array}{l}\text { Min-Max } \\
\text { Normalized } \\
\text { Output } \\
\text { Variables }\end{array}$ & $\begin{array}{l}\text { Inverse } \\
\text { Output } \\
\text { Variables }\end{array}$ & $\begin{array}{l}\text { Min-Max } \\
\text { Normalized } \\
\text { Output } \\
\text { Variables }\end{array}$ \\
\hline MS Excel & Excel Solver & + & + & + & + \\
\hline $\mathrm{R}$ & rDEA & + & + & + & + \\
\hline Python & PyDEA & + & + & + & + \\
\hline Matlab & DEA Toolbox & + & + & + & + \\
\hline
\end{tabular}

The summary of the DEA results for each DMU are presented in Table 3. In this table, the mean for each DMU is the average of the 16 efficiency scores for this DMU. A DMU's standard deviation is the square root of the variance of this DMU's 16 efficiency scores. Coefficient of variation (CV) in this case is a ratio (in \%) of each DMU's standard deviation and mean.

Table 3. Summary of DEA energy efficiency scores for DMUs

\begin{tabular}{|l|l|l|l|}
\hline \multirow{2}{*}{ DMU } & \multicolumn{3}{|l|}{ Summary of DEA Results for DMU Efficiency Scores } \\
\cline { 2 - 4 } & Mean & Standard Deviation & Coefficient of Variation \\
\hline 1 & 0.937 & 0.113 & $12.1 \%$ \\
\hline 2 & 0.986 & 0.026 & $2.6 \%$ \\
\hline 3 & 0.903 & 0.072 & $8.0 \%$ \\
\hline 4 & 1.000 & 0.000 & $0.0 \%$ \\
\hline 5 & 0.779 & 0.135 & $17.3 \%$ \\
\hline 6 & 0.763 & 0.138 & $18.1 \%$ \\
\hline 7 & 0.964 & 0.064 & $6.6 \%$ \\
\hline 8 & 0.786 & 0.178 & $22.7 \%$ \\
\hline 9 & 0.903 & 0.155 & $17.1 \%$ \\
\hline 10 & 0.787 & 0.226 & $28.7 \%$ \\
\hline 11 & 0.888 & 0.088 & $9.9 \%$ \\
\hline 12 & 0.802 & 0.149 & $18.6 \%$ \\
\hline 13 & 0.996 & 0.015 & $1.6 \%$ \\
\hline 14 & 0.721 & 0.150 & $20.8 \%$ \\
\hline 15 & 0.824 & 0.122 & $14.8 \%$ \\
\hline 16 & 0.709 & 0.156 & $22.0 \%$ \\
\hline 17 & 1.000 & 0.000 & $0.0 \%$ \\
\hline & & & \\
\hline
\end{tabular}




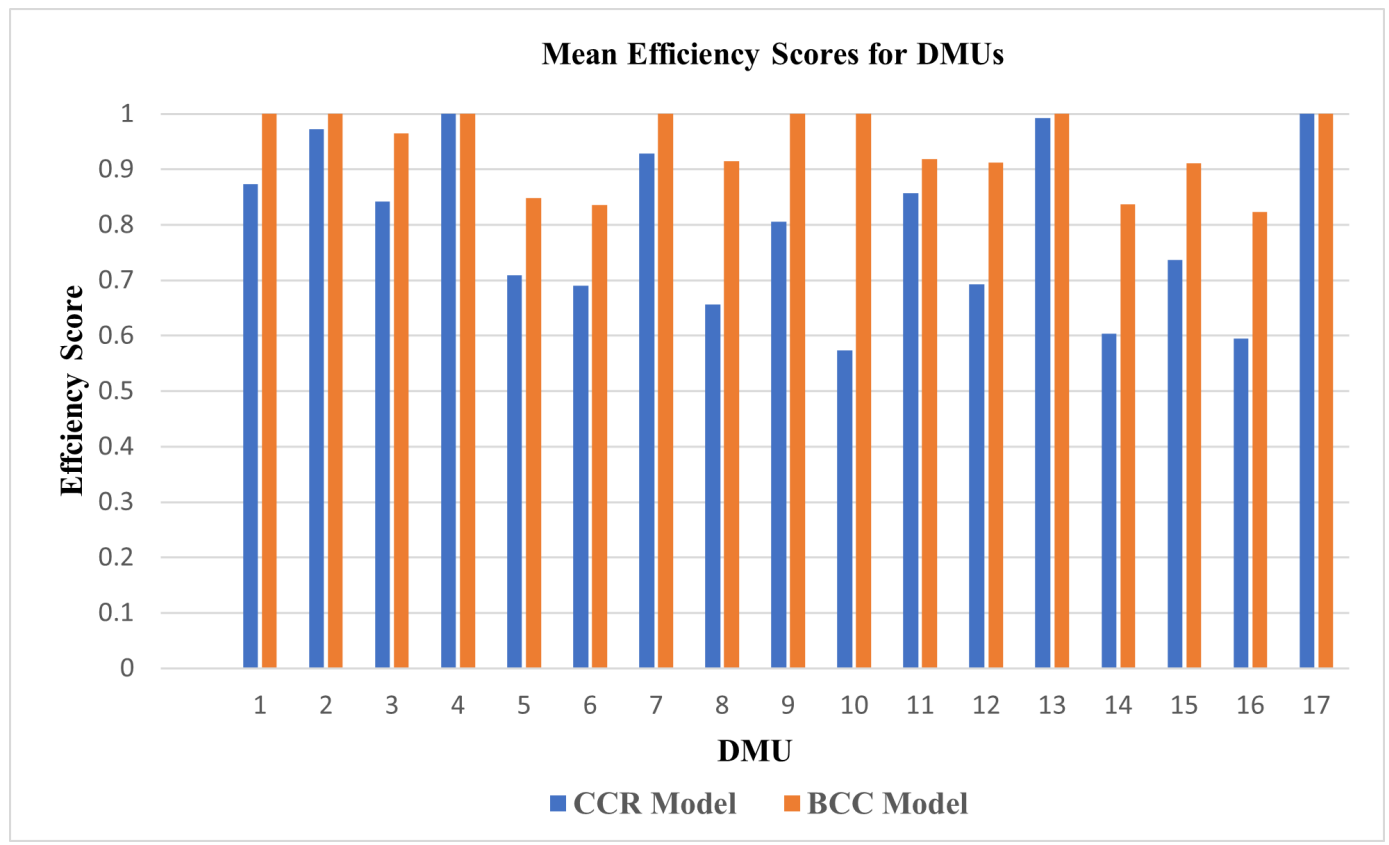

As can be seen from Table 3, there are only 2 DMUs, \#4 and \#17, for which the optimal energy efficiency score of $1(100 \%)$ is the same with a standard deviation of 0 for all 16 efficiency scores of the DEA results. The rest of DMUs have the means of efficiency scores below 1 . Their standard deviations and CVs vary from the lowest values of 0.015 and $1.6 \%$, respectively, for DMU \#13 to the highest values of 0.226 and $28.7 \%$ for DMU \#10. Overall, this indicates that the DEA results in terms of the DMUs' efficiency scores may widely differ across the DEA models and software packages applied in this research.

To further explore this variability (inconsistency) of the DEA results for each DMU, the analysis was done for the differences between the means of efficiency scores for the CCR and BCC models that were developed using all four software packages (Figure 1). The chart in Figure 1 shows that for most DMUs the means of efficiency scores, derived by the CCR and BCC models, are different. Moreover, the means of efficiency scores identified by the BCC models are mostly higher than the respective scores produced by the CCR models. In only two cases, for DMUs \#4 and \#17, these optimal scores are equal, which is similar to the means of efficiency scores for these DMUs in Table 3.

In addition to the chart in Figure 1, the two-sample T-test with unequal variances is applied to compare the CCR and BCC models' mean efficiency scores for each DMU (Table 4). In this test, the hypothesized difference between the respective means is equal to 0 (the population means are statistically equal), with significance $\alpha$ of 0.05 .

The P-values of lower than 0.05 for the two-tail T-test indicate the need to reject the zero-difference hypothesis, and thus the population means of the CCR and BCC models are not statistically equal. This is true for 13 out of 17 DMUs, which is the bulk portion of DMUs. For two DMUs, \#11 and \#13, the null hypothesis may not be rejected because the respective P-values are greater than 0.05 . For two other DMUs, \#4 and 17, the T-test was not applicable, because the standard deviations for these DMUs are equal to 0. The results of one-tail T-tests with P-values of less than 0.05 prove that a DMU's efficiency from the BCC model is typically greater than the same DMU's efficiency produced by the CCR model. This is also confirmed by several DEA literature sources (Coelli et al., 2005; Cooper et al., 2011; Grilo \& Santos, 2015). 
Table 4. T-test for mean efficiency scores using CCR and BCC models

\begin{tabular}{|l|l|l|l|l|l|l|}
\hline \multirow{2}{*}{ DMU } & \multicolumn{2}{|l|}{ Mean Efficiency Scores } & \multirow{2}{*}{ Hypothesized } & \multicolumn{3}{l|}{ P-value } \\
\cline { 2 - 3 } \cline { 7 - 8 } & CCR Model & BCC Model & Difference & T Statistic & One-Tail & Two-Tail \\
\hline 1 & 0.873 & 1.000 & 0 & -2.646 & 0.017 & 0.033 \\
\hline 2 & 0.972 & 1.000 & 0 & -2.532 & 0.020 & 0.039 \\
\hline 3 & 0.842 & 0.965 & 0 & -6.977 & 0.000 & 0.000 \\
\hline 4 & 1.000 & 1.000 & 0 & N/A & N/A & N/A \\
\hline 5 & 0.709 & 0.848 & 0 & -2.345 & 0.017 & 0.034 \\
\hline 6 & 0.690 & 0.835 & 0 & -2.421 & 0.015 & 0.031 \\
\hline 7 & 0.929 & 1.000 & 0 & -2.646 & 0.017 & 0.033 \\
\hline 8 & 0.656 & 0.915 & 0 & -4.232 & 0.001 & 0.002 \\
\hline 9 & 0.806 & 1.000 & 0 & -3.195 & 0.008 & 0.015 \\
\hline 10 & 0.574 & 1.000 & 0 & -16.845 & 0.000 & 0.000 \\
\hline 11 & 0.857 & 0.919 & 0 & -1.468 & 0.084 & 0.168 \\
\hline 12 & 0.693 & 0.912 & 0 & -4.341 & 0.001 & 0.001 \\
\hline 13 & 0.992 & 1.000 & 0 & -1.000 & 0.175 & 0.351 \\
\hline 14 & 0.604 & 0.838 & 0 & -5.035 & 0.000 & 0.000 \\
\hline 15 & 0.736 & 0.911 & 0 & -4.129 & 0.001 & 0.001 \\
\hline 16 & 0.595 & 0.823 & 0 & -4.310 & 0.001 & 0.001 \\
\hline 17 & 1.000 & 1.000 & 0 & N/A & N/A & N/A \\
\hline
\end{tabular}

To further analyze the variability of the DEA results, the energy efficiency scores of all DMUs are compared for the CCR and BCC models with inverse outputs (see Figure 2).

The examination of the charts in Figure 2 leads to a conclusion that the efficiency scores for DMUs are more consistent for the CCR model with inverse output variables. The respective chart in Figure 2 shows a variability of efficiency scores in only three DMUs, \#9, \#11 and \#16. Contrary to that, the BCC model with inverse outputs produces less consistent efficiency scores for a number of DMUs. The variability of efficiency scores can be observed in 9 out of 17 (52.9\% of the total) of DMUs, i.e., \#3, \#5-6, \#8, \#11-12, and \#14-16. The evaluation of the charts in Figure 2 leads to another conclusion that the BCC models produce more DMUs with the efficiency scores of $1(100 \%)$ than the number of these scores with the CCR models. This is another confirmation of the fact that a DMU's efficiency from the BCC model is typically greater than or equal to the same DMU's efficiency produced by the CCR model.

The assessment of efficiency scores for the CCR and BCC models with min-max normalized outputs (Figure 3 ) points to the same conclusions as those identified from the charts in Figure 2. In addition, both CCR and BCC models with min-max outputs tend to develop higher efficiency scores than the efficiency scores of the same models with inverse outputs in Figure 2. As can be also visualized from the charts in Figure 2 and Figure 3, the efficiency scores for DMUs are the more consistent (with least variability) for the CCR model with inverse output variables.

In applying each analytics package in this research, the goal was to be as consistent as possible in using the same models and input/output variables. However, there are some software-related differences in the way the DEA algorithms are developed and run in the respective analytics packages. For example, the Matlab's DEA Toolbox utilizes a two-stage DEA optimization model and dualsimplex method for LP optimization (Alvarez et al., 2020), whereas the other three analytics software 

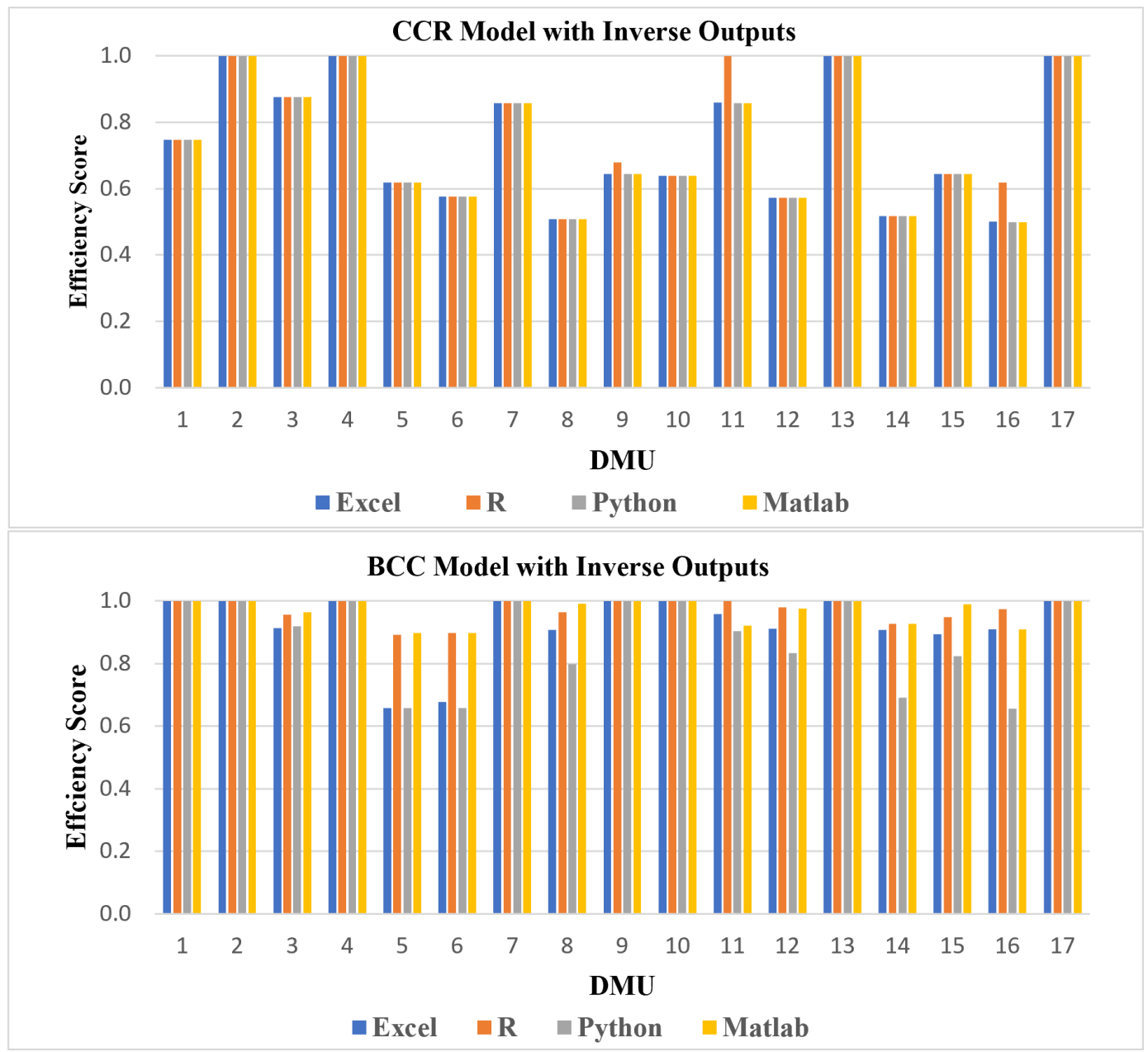

employ a one-stage DEA optimization with a standard (non-dual) simplex method (PyDEA, 2021; Simm, 2020; Zhu, 2014). The R's rDEA package does not specify which form of the DEA model is used - Multiplier or Envelopment Form (Simm, 2020), while for the other three analytics software the traditional Multiplier Form of the DEA model is being applied. The Excel DEA model is formulated as a spreadsheet model and needs to be solved by running Excel Solver for each DMU (Zhu, 2014). Overall, the PyDEA library (PyDEA, 2021), with the number of possible options, methods, and algorithms used in DEA, is the most comprehensive and versatile DEA option among the analytics software used in this research. All these may contribute to the differences in the results presented in Figures 2 and 3.

To quantitatively measure a degree of consistency within DMU efficiency scores, the authors apply Cronbach's $\alpha$ coefficient of internal consistency. It measures how closely related a set of items are as a group (Nunnally \& Bernstein, 1994). In this research, the Cronbach's $\alpha$ coefficients are used for the groups of DMU efficiency scores produced by the CCR and BCC models with inverse and min-max output variables that were run on Excel, R, Python, and Matlab (Table 5).

According to Nunnally and Bernstein (1994), a Cronbach coefficient of .70 or higher is considered acceptable in terms of internal consistency. Applying this criterion to the Cronbach's $\alpha$ from Table 
Figure 3. Efficiency scores for CCR and BCC models with min-max outputs

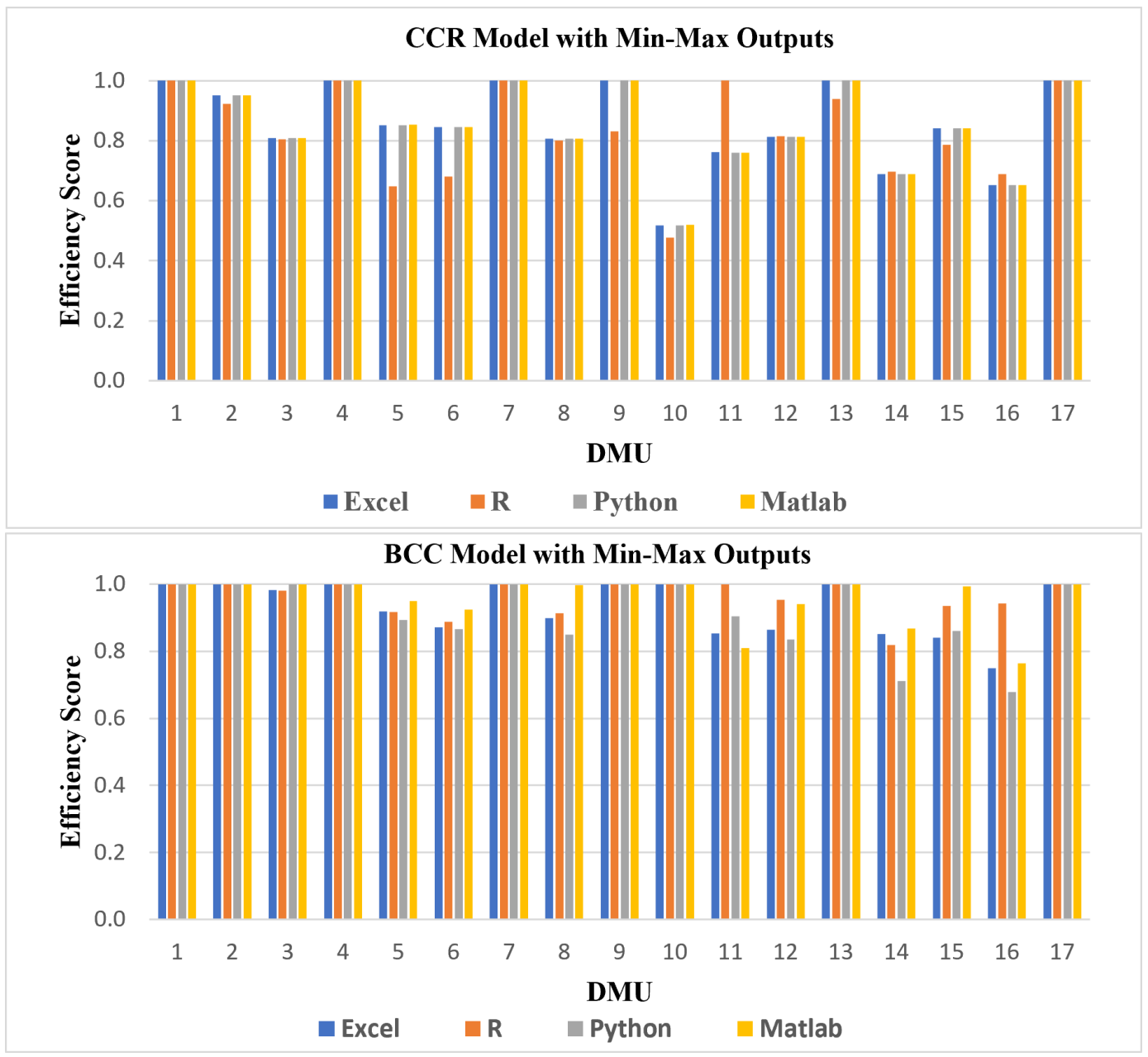

Table 5. Internal consistency (reliability) of DEA results

\begin{tabular}{|l|l|l|}
\hline \multirow{2}{*}{ Parameters } & \multicolumn{2}{|l|}{ Cronbach's $\boldsymbol{\alpha}$ Coefficients } \\
\cline { 2 - 3 } & CCR Model & BCC Model \\
\hline Inverse Outputs & 0.997 & 0.848 \\
\hline Min-Max Outputs & 0.970 & 0.817 \\
\hline Excel Solver & 0.739 & 0.625 \\
\hline R - rDEA & 0.732 & 0.716 \\
\hline Python - PyDEA & 0.908 & 0.707 \\
\hline Matlab - DEA Toolbox & 0.719 & 0.660 \\
\hline
\end{tabular}


5, it can be observed that internal consistency of both CCR and BCC models is higher than the acceptable level of 0.7. However, the highest values of those Cronbach's $\alpha$ coefficients are associated with the CCR models, and, specifically, the CCR model with inverse output variables. This confirms the previously discussed results from the charts in Figures 2 and 3. Therefore, it can be concluded that in this research the CCR model with inverse outputs delivers the most consistent/reliable results with various software applied.

The data in Table 5 also provides information on Cronbach's $\alpha$ coefficients for the four utilized software packages. These coefficients show that, for each software, the CCR models have higher consistency coefficients than those for the BCC models. In fact, for Excel and Matlab, the values of Cronbach's $\alpha$ coefficients for the BCC models are below the acceptable level of 0.7. The highest consistency coefficient of 0.908 is achieved by the Python-based CCR model. The authors would also want to point out that the PyDEA is an open-source software, and thus there is no software license and maintenance fees attached to it. Contrary, there are associated license and maintenance fees for Microsoft Excel and Matlab, which makes these software packages more expensive. Overall, the Python's PyDEA package appears to be in this research the most consistent (reliable) and effective analytics software package for DEA-based energy efficiency analysis and optimization in buildings.

\section{CONCLUSION}

The main objective of this research was to identify the most effective DEA model(s) and associated analytics software for measuring, comparing, and optimizing energy efficiency in buildings. This requires applying different DEA models and various analytics software. In this context, a variety of literature sources were reviewed to understand DEA methodologies, models, and input/output variables applied for buildings' energy efficiency comparison.

Overall, the analysis of literature sources demonstrated that both CCR and BCC models are being applied in measuring energy efficiency in buildings. However, this literature search did not identify any discussion or comparison of these models for measuring building energy efficiency, which the authors considered as a gap in the existing DEA research. Another identified gap is that the commonly described in the literature sources DEA output variables like building floor space and number of occupants, should be, in fact, inputs in the DEA models. At the same time, frequently used in practice energy indices like energy consumption per square foot or per number of occupants, should be applied as output variables in DEA models. One more gap revealed from the literature review is associated with the lack of consideration for effectiveness and consistency of commonly applied DEA-related software packages in comparing and optimizing building energy efficiency.

Based on the recognized DEA gaps, a research methodology was developed to address and resolve these gaps. First, the four input and three output variables for DEA were identified that truly reflect the way that energy efficiency comparison and optimization are done in buildings. Second, the methodology continued with managing undesirable outputs by utilizing the inverse and min-max normalized output variables. Third, the decision was also made to apply both CCR and BCC models with four DEA-related analytics packages including Excel Solver, R's $r D E A$, Python's PyDEA, and Matlab's DEA Toolbox.

The results of using these analytics packages indicated that the DMU's efficiency scores are mostly varying across different models and software packages applied. In particular, the means of DMUs' efficiency scores identified by the BCC models are mostly greater than the means of efficiency scores produced by the CCR models for the respective DMUs. The means of efficiency scores of all DMUs were compared for the CCR and BCC models with inverse outputs versus the same models with min-max normalized outputs. The comparison of these models by utilizing Cronbach's $\alpha$ led to a conclusion that the DMUs' efficiency scores are the most consistent with the CCR model, and, specifically, the CCR model with inverse output variables. In addition, the Cronbach's $\alpha$ coefficients for the four applied analytics packages showed that the highest reliability coefficient appeared to be 
for the CCR model run with the PyDEA package. It was therefore concluded that the CCR model with inverse output variables provided the most consistent/reliable results regardless of the software application utilized, with the Python's PyDEA package being the most reliable and effective in terms of running the CCR model. Overall, based on the achieved reliability/consistency of the results and economic consequence of using Python-based software (open-source software with no fees), the authors recommended to apply the PyDEA package over other discussed analytics software for comparing and optimizing buildings' energy efficiency.

The described in this paper results have important managerial implications in using the DEA models for measuring, comparing, and optimizing energy efficiency in buildings. First, the DEA model will be more effective and practice-oriented by introducing energy efficiency indices as DEA output variables and applying the space (floor) area and number of occupants as input variables. Second, the usage of the most reliable and effective DEA model and software package (PyDEA with CCR model and inverse output variables) will enhance the measurement, comparison, and optimization of energy efficiency in buildings. Finally, based on the best performing DEA model and software package, data analytics professionals can develop decision support systems (DSS) that will extend the usage of DEA models to end-users, e.g., building energy managers, engineers, and specialists. 


\section{REFERENCES}

Alvarez, I. C., Barbero, J., \& Zofio, J. L. (2020). A data envelopment analysis toolbox for MATLAB. Journal of Statistical Software, 95(3), 1-49. doi:10.18637/jss.v095.i03

Ashuri, B., Wang, J., Shahandashti, M., \& Baek, M. (2019). A data envelopment analysis (DEA) model for building energy benchmarking. Journal of Engineering Design and Technology, 17(4), 747-768. doi:10.1108/ JEDT-08-2018-0127

Banker, R. D., Charnes, A., \& Cooper, W. W. (1984). Some models for estimating technical and scale inefficiencies in data envelopment analysis. Management Science, 30(9), 1078-1092. doi:10.1287/mnsc.30.9.1078

Banker, R. D., Cooper, W. W., Seiford, L. M., Thrall, R. M., \& Zhu, J. (2004). Returns to scale in different DEA models. European Journal of Operational Research, 154(2), 345-362. doi:10.1016/S0377-2217(03)00174-7

Charnes, A., Cooper, W. W., \& Rhodes, E. (1978). Measuring the efficiency of decision making units. European Journal of Operational Research, 2(6), 429-442. doi:10.1016/0377-2217(78)90138-8

Coelli, T. J., Rao, D. S. P., O’Donnell, C. J., \& Battese, G. E. (2005). An introduction to efficiency and productivity analysis. Springer.

Cooper, W. W., Seiford, L. M., \& Zhu, J. (2011). Handbook on data envelopment analysis. Springer. doi:10.1007/978-1-4419-6151-8

Daraio, C., Kerstens, K. H. J., Nepomuceno, T. C. C., \& Sickles, R. C. (2019). Productivity and efficiency analysis software: An exploratory bibliographical survey of the options. Journal of Economic Surveys, 33(1), 85-100. doi:10.1111/joes.12270

EAI (U.S. Energy Information Administration). (2020). How much energy is consumed in U.S. buildings? https:// www.eia.gov/tools/faqs/faq.php?id=86\&t=1

Emrouznejad, A., \& Amin, G. R. (2009). DEA models for ratio data: Convexity consideration. Applied Mathematical Modelling, 33(1), 486-498. doi:10.1016/j.apm.2007.11.018

Energy Star. (2018). Portfolio manager technical reference: Energy star score. https://www.energystar.gov/ buildings/tools-and-resources/portfolio-manager-technical-reference-energy-star-score

Fairey, P., \& Goldstein, D. B. (2016). Metrics for energy efficient buildings: How do we measure efficiency? 2016 ACEEE Summer Study on Energy Efficiency in Buildings. http://www.aceee.org

Fare, R., \& Grosskopf, S. (2004). Modelling undesirable factors in efficiency evaluation [Comment]. European Journal of Operational Research, 157(1), 242-245. doi:10.1016/S0377-2217(03)00191-7

Goldstein, D. B., \& Eley, C. (2014). A classification of building energy indices. Energy Efficiency, 7(2), 353-375. doi:10.1007/s12053-013-9248-0

Grilo, A., \& Santos, J. (2015). Measuring efficiency and productivity growth of new technology-based firms in business incubators: The Portuguese case study of Madan Parque. TheScientificWorldJournal, 3, 1-22. doi:10.1155/2015/936252 PMID:25874266

Grösche, P. (2009). Measuring residential energy efficiency improvements with DEA. Journal of Productivity Analysis, 31(2), 87-94. doi:10.1007/s11123-008-0121-7

Halkos, G. E., \& Polemis, M. L. (2018). The impact of economic growth on environmental efficiency of the electricity sector: A hybrid window DEA methodology for the USA. Journal of Environmental Management, 211, 334-346. doi:10.1016/j.jenvman.2018.01.067 PMID:29425942

Homayounfar, M., Amirtteimoori, A. R., \& Toloie-Eshlaghy, A. (2014). Production planning considering undesirable outputs - a DEA based approach. International Journal of Applied Operations Research, 4(3), 1-11.

Iliyasu, A., Mohamed, Z. A., \& Terano, R. (2015). Data envelopment analysis models and software packages for academic purposes. Pertanika Journal of Scholarly Research Reviews, 1(1), 27-32.

Jahanshahloo, G. R., Hosseinzadeh Lotfi, F., Shoja, N., Tohidi, G., \& Razavyan, S. (2005). Undesirable inputs and outputs in DEA models. Applied Mathematics and Computation, 169(2), 917-925. doi:10.1016/j.amc.2004.09.069 
Kavousian, A., Rajagopal, R., \& Fischer, M. (2015). Ranking appliance energy efficiency in households: Utilizing smart meter data and energy efficiency frontiers to estimate and identify the determinants of appliance energy efficiency in residential buildings. Energy and Building, 99, 220-230. doi:10.1016/j.enbuild.2015.03.052

Lee, W.-S. (2008). Benchmarking the energy efficiency of government buildings with data envelopment analysis. Energy and Building, 40(5), 891-895. doi:10.1016/j.enbuild.2007.07.001

Lee, W.-S., \& Lee, K.-P. (2009). Benchmarking the performance of building energy management using data envelopment analysis. Applied Thermal Engineering, 29(16), 3269-3273. doi:10.1016/j. applthermaleng.2008.02.034

Liu, F., \& Zhang, M. (2017). Production planning based on DEA profit efficiency models. International Journal of Business Analytics, 4(3), 1-14. doi:10.4018/IJBAN.2017070101

Mathew, P. A., Dunn, L. N., Sohn, M. D., Mercado, A., Custudio, C., \& Walter, T. (2015). Big-data for building energy performance: Lessons from assembling a very large national database of building energy use. Applied Energy, 140, 85-93. doi:10.1016/j.apenergy.2014.11.042

Molinos-Senante, M., Encinas, F., \& Ureta, F. (2016). Benchmarking the energy performance of office buildings: A data envelopment analysis approach. Revista Electronica de Comunicaciones y Trabajos de ASEPUMA, 16, 179-190.

Nguyen, N.-T., \& Nguyen, L.-X. T. (2019). Applying DEA model to measure the efficiency of hospitality sector: The case of Vietnam. International Journal of Analysis and Applications, 17(6), 994-1018.

Nunnally, J. C., \& Bernstein, I. C. (1994). Psychometric theory. McGraw-Hill.

Olesen, O. B., Petersen, N. C., \& Podinovski, V. V. (2015). Efficiency analysis with ratio measures. European Journal of Operational Research, 245(2), 446-462. doi:10.1016/j.ejor.2015.03.013

Olesen, O. B., Petersen, N. C., \& Podinovski, V. V. (2017). Efficiency measures and computational approaches for data envelopment analysis models with ratio inputs and output. European Journal of Operational Research, 261(2), 640-655. doi:10.1016/j.ejor.2017.02.021

Orvis, R., Aggarwal, S., \& O’Boyle, M. (2016). Metrics for energy efficiency: Options and adjustment mechanisms. https://energyinnovation.org/publication/metrics-energy-efficiency-options-adjustment-mechanisms/

PyDEA documentation - GitHub pages. (2021). https://araith.github.io/pyDEA/

Scheel, H. (2001). Undesirable outputs in efficiency valuations. European Journal of Operational Research, 132(2), 400-410. doi:10.1016/S0377-2217(00)00160-0

Seiford, L. M., \& Zhu, J. (2002). Modelling undesirable factors in efficiency evaluation. European Journal of Operational Research, 142(1), 16-20. doi:10.1016/S0377-2217(01)00293-4

Simm, J. (2020). rDEA: Robust data envelopment analysis (DEA) for $R$. https://cran.r-project.org/package=rDEA

Sopko, J., \& Kocisova, K. (2018). The problem of using data in DEA models. Central European Conference in Finance and Economics (CEFE2018), 9, 573-584.

Wang, E., Shen, Z., Alp, N., \& Barry, N. (2015). Benchmarking energy performance of residential buildings using two-stage multifactor data envelopment analysis with degree-day based simple-normalization approach. Energy Conversion and Management, 106, 530-542. doi:10.1016/j.enconman.2015.09.072

Wang, J. (2017). Benchmarking building energy in the multifamily industry: A data envelopment analysis (DEA) model. Georgia Institute of Technology, 5, 1-93.

Xu, T., You, J., Li, H., \& Shao, L. (2020). Efficiency evaluation based on data envelopment analysis: A literature review. Energies, 13(3548), 1-20.

Yang, H., \& Pollitt, M. (2009). Incorporating both undesirable outputs and uncontrollable variables into DEA: The performance of Chinese coal-fired power plants. European Journal of Operational Research, 197(3), 1095-1105. doi:10.1016/j.ejor.2007.12.052

Yoon, S.-H., \& Park, C.-S. (2017). Objective building performance benchmarking using data envelopment analysis and Monte Carlo sampling. Sustainability, 9(780), 1-12. doi:10.3390/su9050780 
Zakowska, I., \& Maciek, G.-C. (2020). Data envelopment analysis applications in primary health care: A systematic review. Family Practice, 37(2), 147-153. PMID:31605609

Zhu, J. (2014). Quantitative models for performance evaluation and benchmarking: Data envelopment analysis with spreadsheets. Springer International Publishing.

Zinovy Radovilsky is a Professor of Management in the Department of Management at California State University, East Bay. He has been a chair of this department in 2012-2016 and is now a coordinator of Operations Management and Analytics in the same department. His research interests include business data analytics, optimization, time series forecasting, supply chain planning and scheduling, e-commerce business modeling, and enterprise resource planning. He has published over 35 research papers in peer-reviewed journals, four book chapters and one textbook. He served as an editor and member of the board of two research journals.

Pallavi Taneja received an MS degree in Business Analytics from California State University, East Bay in 2019. In 2020, she was employed as a Data Analyst at Grocery Outlet Inc. in Emeryville, CA and in 2021 she is employed as a Sr. Analyst - Digital Marketing at Firewood Marketing (now a part of Media.Monks) in San Francisco, CA.

Payal Sahay received her MS in Business Analytics from California State University, East Bay in 2019. She is employed by Buzzer Sports since 2021 as a Senior QA Lead for their analytics products. 